\title{
Measuring the impact of trigeminal neuralgia pain: the Penn Facial Pain Scale-Revised
}

This article was published in the following Dove Press journal: Journal of Pain Research

\author{
Tara Symonds' \\ Jason A Randall' \\ Deborah L Hoffman ${ }^{2}$ \\ Joanna M Zakrzewska ${ }^{3}$ \\ William Gehringer ${ }^{4}$ \\ John YK Lee ${ }^{5}$ \\ 'Clinical Outcomes Solutions, Clinical \\ Outcome Assessments, Folkestone, \\ UK; ${ }^{2}$ Biogen Inc., Cambridge, MA, USA; \\ ${ }^{3}$ Eastman Dental Hospital - University \\ College London Hospitals, Division \\ of Diagnostic, Surgical and Medical \\ Sciences, London, UK; ${ }^{4} \mathrm{Clinical}$ \\ Outcomes Solutions, Tucson, AZ, USA; \\ ${ }^{5}$ University of Pennsylvania, Perelman \\ School of Medicine, Philadelphia, PA, \\ USA
}

Background and objective: The Penn Facial Pain Scale (Penn-FPS) was originally developed as a supplemental module to the Brief Pain Inventory Pain Interference Index (BPI-PII) in order to fully assess the impact of trigeminal neuralgia (TN) pain on patients' health-related quality of life (HRQoL). The current objective is to create and establish the content validity of a new stand-alone version of the measure, the Penn-FPS-Revised (Penn-FPS-R).

Methods: Twenty participants (15 USA and 5 UK) with confirmed TN engaged in concept elicitation and cognitive debriefing interviews. These semi-structured interviews allowed participants to spontaneously describe the ways in which TN impacts on HRQoL and report on the extent to which the Penn-FPS and BPI-PII measure concepts are most relevant to them. Participants were also asked to report on the suitability of the instructions, recall period, and response options.

Results: Concept elicitation revealed nine themes involving TN restrictions on daily activities and HRQoL, including: "talking," "self-care," "eating," "eating hard foods/chewing foods," "daily activities," "activities with temperature change," "touching," "mood," and "relationships." Cognitive debriefing confirmed that all of the Penn-FPS concepts and some of the BPI-PII concepts ("mood," "general activities," and "relations with others") were relevant, although some items required edits to better capture individuals' experiences. The impact of temperature and/ or weather on activities was also identified as an important concept that is not captured by the Penn-FPS or BPI-PII. Participants confirmed the acceptability of recall period, instructions, and response options. Results from the interviews were applied to create the Penn-FPS-R, a new brief outcome measure that assesses the impacts of TN most important to patients.

Conclusion: The Penn-FPS-R is a new 12-item HRQoL outcome measure with content validity that can be used to assess and monitor the impact of TN treatment interventions in both clinical practice and research.

Keywords: content validity, concept elicitation, cognitive debriefing, Penn Facial Pain Scale, trigeminal neuralgia, PRO development, patient reported outcome

\section{Introduction}

Trigeminal neuralgia (TN) is an uncommon neuropathic disorder characterized by debilitating episodic facial pain. ${ }^{1-3}$ The International Association for the Study of Pain defines TN as "sudden, usually unilateral, severe, brief, stabbing, recurrent episodes of pain in the distribution of one or more branches of the trigeminal nerve." ${ }^{4}$ Historically, TN has been called the "suicide disease" because of the severe pain associated with the condition. ${ }^{5}$

Excruciating pain severity is considered intractable or difficult to treat and can be triggered by normal activities, such as talking, chewing, and swallowing. ${ }^{6}$ The impact
Correspondence: Jason A Randall

Clinical Outcomes Solutions, Unit 68 Basepoint, Shearway Business Park,

Shearway Road, Folkestone,

CTI9 4RH, UK

Tel +44I30366I026

Email jason.randall@clinoutsolutions.com 
of pain on patients with $\mathrm{TN}$ includes a decreased quality of life and impaired daily functioning, which indicates that TN pain is a substantial burden to patients. ${ }^{6-8}$ The disease burden may result from suboptimal management strategies, complications from treatments, and resistance of TN to treatment. Therefore, in assessing the success of treatment, measuring impact on health-related quality of life (HRQoL) is an important end point.

Robust outcome measures are needed to assess and monitor the impact of treatment interventions. Until recently, however, no TN-specific measures existed. The original Penn Facial Pain Scale (Penn-FPS; previously called the Brief Pain Inventory - Facial, ${ }^{9-11}$ then renamed Penn-FPS ${ }^{12}$ ) was designed to fill this need. The Penn-FPS was developed as a supplemental module to the Brief Pain Inventory Pain Interference Index (BPI-PII). ${ }^{9-11}$ The Penn-FPS assesses interference with activities of daily living specific to TN. The scale's psychometric properties are evidenced with strong reliability and validity. ${ }^{10,12}$ Advantages of the Penn-FPS include its disease-specific questions, practical administration verbally or on paper, and its comprehensive assessment of impact of $\mathrm{TN}$ on daily activities, ${ }^{12}$ which mirrors the concerns raised by $\mathrm{TN}$ patients who were interviewed about living with TN. ${ }^{13}$

The Penn-FPS helped expand and advance the impact assessment of TN on affected individuals. However, it has limitations that are important to address. Most importantly, content validity cannot be confirmed because patients were not involved in development of the items. According to the Food and Drug Administration Guidance for Industry on Patient Reported Outcomes, ${ }^{14}$ content validity is a crucial part of measure development and insures that all concepts of interest from patients are incorporated in the measure. This is an essential first step as any additional psychometrics only build upon that foundation. Second, even though the BPI-PII only includes 7 items, it is likely that not all are relevant to participants with TN. For example, TN would not be expected to have an impact on "walking ability."

The purpose of the current research is to understand what aspects of TN pain are most important to individuals with $\mathrm{TN}$, and to use that information to potentially modify the existing Penn-FPS to create a new, stand-alone outcomes measure with content validity.

\section{Methods}

\section{Study design and conduct}

This study employed a qualitative research approach with semi-structured interviews, ${ }^{15,16}$ which allowed for the best exploration of participants' subjective thoughts and experience of living with TN. Ethical review boards (Copernicus Group Independent Review Board, Cary, NC, USA; University College London, London, UK) approved the study and study documents. The study was performed in accordance with the Declaration of Helsinki and US 21 Code of Federal Regulations. ${ }^{17}$ Participants received a small stipend for their participation.

\section{Patient eligibility}

Eligible participants were between the ages of 18 and 80 years with a confirmed clinical diagnosis of TN (of at least 3 months). Participants must have experienced painful TN paroxysms within the past 14 days (rated at an intensity of 4 or more on the pain numeric rating scale [NRS] and between a fraction of a second to 2 minutes in duration). The pain was required to have at least one of the following characteristics: "intense," "sharp," "superficial," or "stabbing." The pain could not be attributed to another neurological deficit or disorder.

Patients were identified through the UK TN Association and clinical databases in the USA (sites in New Orleans, LA; St Louis, MO; and Baltimore, MD). All participants were required to sign and date an informed consent document before being enrolled onto the study. Before entering the study, treating clinicians were required to confirm eligibility. All data were de-identified before analysis. The variation in site location was included to maximize geographic diversity and to allow for a broad spectrum of participants to be recruited for the study. The interviews were conducted at a place most convenient to the participant, either at his or her local clinic or at an interview facility.

\section{Interviews}

All interviews were semi-structured, conducted face-to-face by an experienced interviewer, and took no more than 60 minutes. ${ }^{15,16}$ The first half of the interview involved concept elicitation and the second half involved the participant completing and cognitively debriefing the Penn-FPS and BPI-PII.

The initial part of the discussion was open-ended and focused on eliciting information about the impact of TN on HRQoL, and included questions such as: "Can you tell me a couple of general things about living with trigeminal neuralgia?", "Describe how having trigeminal neuralgia impacts your life?", and "What specifically has been impacted in your life due to your trigeminal neuralgia?" The second half of the interview acted as a cognitive debrief of the BPI-PII and the Penn-FPS (Figure 1), and included questions such as: "What were you thinking about when answering this question?" and "How easy or difficult was it to choose a response?" 


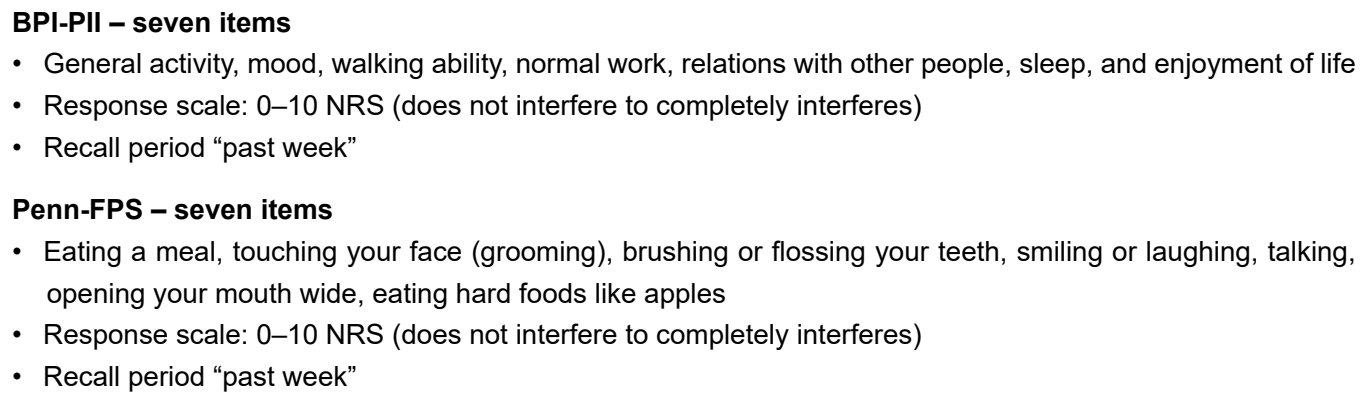

Figure I Measures to be debriefed.

Abbreviations: BPI-PII, Brief Pain Inventory Pain Interference Index; NRS, numeric rating scale; Penn-FPS, Penn Facial Pain Scale.

\section{Analytic approach}

All interviews were transcribed verbatim and analyzed using thematic analysis ${ }^{18}$ in ATLAS.ti Version 7.0. Thematic analysis is an approach that is widely used in the health sciences and is well accepted as a valid approach. ${ }^{18}$ The accuracy of thematic analysis was confirmed by comparing independent themes of different researchers on a selection of transcripts. There was a high level of agreement about the major themes to be retained and information that was not supported.

\section{Results}

\section{Demographic information}

In total, 20 participants completed the study, 15 in the USA and 5 in the UK. Participant ages ranged from 43 to 72 years, with a mean of 57.5 years $(\mathrm{SD}=8.64)$. There were 3 males and 17 females. Participants were identified as American Indian $(\mathrm{n}=1,5 \%)$, African American/Hispanic $(\mathrm{n}=1,5 \%)$, African American $(n=5,25 \%)$, and Caucasian $(n=13,65 \%)$. Over the previous 2 weeks, mean pain was $6.85(\mathrm{SD}=2.34)$ on a 0-10 point NRS, where 0 was "no pain" and 10 was "worst pain imaginable." Participants varied widely when describing the longest period of remission, with reports ranging from 5 minutes to 13 months.

All participants were receiving treatment for TN. A wide range of medications were prescribed, with the most common being gabapentin $(n=7,35 \%)$ and carbamazepine $(n=3,15 \%)$. Despite high average pain scores, the clinicians reported that the medication being taken was effective at treating the pain of most participants $(n=13,65 \%)$. Most participants $(\mathrm{n}=8,40 \%)$ had undergone surgery to treat their TN. Of the 8 participants, $3(37.5 \%)$ had microvascular decompression, $2(25 \%)$ had a stereotactic radiosurgery, $1(12.5 \%)$ had a craniotomy (additional detail not provided by clinician),
$1(12.5 \%)$ had a cyber-knife procedure, and $1(12.5 \%)$ participant had cryosurgery.

\section{Concept elicitation}

Thematic analysis of participants' spontaneous reports revealed 9 TN pain-related HRQoL impacts. Seven were focused on daily activities ("talking," "self-care," "eating," "eating hard foods/chewing foods," "daily activities," "activities with temperature change," and "touching") and 2 related to "mood" and "relationships" impacts. Participants' quotes are presented in Table 1. There was no difference between US and UK cohorts, with regard to concepts discussed.

\section{Cognitive debriefing of BPI-PII}

Three items from the BPI-PII were identified as relevant to all individuals with TN and were supported in the concept elicitation section: "general activities," "mood," and "relations with other people." Based on feedback, these were rephrased as "daily activities (for example, work, exercise, and housework)," "mood (the way you are feeling)," and "relationships (for example, friends, family, partners, etc.)," respectively. The items that were not relevant included: "walking ability," "normal work," "sleep," and "enjoyment of life." All participants highlighted that it was easy to complete and understand, with suitable response options and recall period.

\section{Cognitive debriefing of Penn-FPS}

Participants suggested that all concepts in the Penn-FPS were relevant, although minor amendments were necessary to improve relevance on some items. Participant feedback indicated that the item "eating hard foods" should be rephrased to "biting and chewing" and the item "touching your face 
Table I Concept elicitation themes

\begin{tabular}{|c|c|c|}
\hline Theme & Example quote & $\begin{array}{l}\text { Number of } \\
\text { participants }\end{array}$ \\
\hline Talking & $\begin{array}{l}\text { "Actually, um, well, well, uh ... I couldn't talk at all but that, that was a phase I went through. I had } \\
\text { to write everything." P03-002 } \\
\text { "talking was really painful ... I could barely speak at times." P02-003 } \\
\text { "Talking, absolutely [affected]. ... I was able to carry on with my work was actually, erm, using, erm, } \\
\text { Google Hangout, but rather than speaking, typing." P04-005 }\end{array}$ & $15 / 20$ \\
\hline Self-care & $\begin{array}{l}\text { "Well, brushing and flossing can be excruciating ... washing my face, putting moisturizing creams on } \\
\text { my face [provokes an attack] ... I try to never touch my face." P02-003 } \\
\text { "Washing my face can be a challenge because it ... This, the side of my face is very sensitive when } \\
\text { it's active, and so I just, I just have to really be cautious about it." P0I-005 } \\
\text { "Cleaning teeth, washing your face, well, itching [impacted]." P04-003 }\end{array}$ & $17 / 20$ \\
\hline Eating & $\begin{array}{l}\text { "Eating in general [is affected], and that's the, I try to eat soft foods like oatmeal. ... I had an attack } \\
\text { one time and I said, okay, let me try eating, eating some soup and the salt in the soup triggered it." } \\
\text { P03-002 } \\
\text { "It [eating], it agitates my face ... You know from the chewing, like moving your mouth." P03-00 I } \\
\text { "I puree my foods so I don't go socially anywhere, out to dinner. Um, nobody understands it." P0I-006 }\end{array}$ & $19 / 20$ \\
\hline Eating hard foods & $\begin{array}{l}\text { "hmm, an apple probably is okay. Um, sometimes it's tough to eat, uh, meat, something that requires } \\
\text { more chewing ... I mean to me, biting into an apple, yes, that's hard, but to me, eating an apple is } \\
\text { not as hard as eating a steak or chewing a salad." POI-005 } \\
\text { "If you can't eat a meal, you can't eat apples [or other hard foods] ... It's such a no-no as far as TN } \\
\text { is concerned, eating hard foods even when they haven't got the pain." P04-002 } \\
\text { "when I'm having an episode, I can't eat anything, whether it be hard, soft, or whatever." P04-0005 }\end{array}$ & $12 / 20$ \\
\hline Touching & $\begin{array}{l}\text { "I try to never touch my face." P02-003 } \\
\text { "you can't touch your face." P03-002 } \\
\text { "somebody will come up to me and go to give me a hug and I'm lurching back away from them [for } \\
\text { fear of touching my face]." P04002 }\end{array}$ & $1 \mathrm{I} / 20$ \\
\hline $\begin{array}{l}\text { Activities with } \\
\text { temperature change }\end{array}$ & $\begin{array}{l}\text { "[the number of attacks] It depends on the weather ... I could go outside right now and not a thing } \\
\text { happen. It could, and the wind could be blowing or I could go outside and it could bring me to my } \\
\text { knees because it's so bad." POI-006 } \\
\text { "Air conditioning [trigger] ... And cold weather [trigger] ... Winter is not, wintertime is not a } \\
\text { good time for me... And like I said, summertime is good for me and the heat, but in and out of air } \\
\text { conditioning buildings it's, it flares up again, it's the cold.” P03-00 I }\end{array}$ & $8 / 20$ \\
\hline Daily activities & $\begin{array}{l}\text { "I have to be completely drugged to do the dishwasher or a load of laundry or, um, any kind of ... } \\
\text { putting sheets on the bed, and I could go through all of that and nothing ever happened, and l'll go to } \\
\text { sit down, and it will hit me. Or it won't. You, you don't know." P0I-006 } \\
\text { "So it, it can very much interfere with your daily activities. Hm." P03-002 } \\
\text { "Because I did have an attack at a grocery store and, but it lasted for like maybe } 5 \text { minutes and all I } \\
\text { could do was just hold on to the basket." P0I-008 }\end{array}$ & $15 / 20$ \\
\hline Mood & $\begin{array}{l}\text { "My mood, oh, yeah, God, absolutely. (Laughter) I mean, you know, you just hit rock bottom.” P04-005 } \\
\text { "Um, I, I, I think it's depressed, my mood." POI-0II } \\
\text { "I have no life ... My mood, there is no mood. There's either you keep trying or you give up. Money } \\
\text { will run out and I'll have to give up soon.” POI-006 }\end{array}$ & $13 / 20$ \\
\hline Relationships & $\begin{array}{l}\text { “I mean just like the little simple stuff you know [restricted due to TN] I mean, I can't like, I mean I } \\
\text { don't see anybody, I don't have a boyfriend you know or anything like that.” P0I-009 } \\
\text { "on relationships is that suddenly I have become an ill person, whereas I wasn't, you know ... it's } \\
\text { probably easier for me, as a sufferer, than it is for them [husband and kids] to see my suffering." } \\
\text { P04-005 }\end{array}$ & $14 / 20$ \\
\hline
\end{tabular}

Note: "P" indicates participant; the first two digits refer to the site ID whilst the final 3 digits refer to the participant ID number.

(including grooming)" should be separated into two items: "self-care (including washing face or hair, shaving, applying makeup)" and "touching your face (including moving stray hairs, hugging, kissing, itching)." In addition, based on participants' discussion during concept elicitation and feedback on the measure, a new item capturing the impact of weather and temperature change was added ("Activities with temperature change [moving outside, between air-conditioned rooms]"); for example: "I think an important question would be, umm, how the weather affects pain cause that's defiantly a factor when you have TN. Because the wind and the cold, um, just that's a trigger for everyone" [site ID 01; participant ID 004]. All participants highlighted that the measure was easy to complete, understand, had a suitable recall period and response options. 


\section{Measure development}

Results were applied to create the new 12-item Penn-FPS-R (Table 2). One minor change to the instructions was added to increase clarity. The new instructions are "Circle the ONE number that best describes how much, during the past week, your pain has interfered with ..." (versus "Circle the ONE number that best describes how, during the past week, pain has interfered with your ..."). No changes were made to the 1-week recall period or response options as participants confirmed that the current format was acceptable. Table 2 details item development.

\section{Discussion}

Sound outcome measures are needed to assess the impact of new treatment interventions in clinical practice and research. The current research built upon previous work with the PennFPS and supported the development of a new stand-alone TN outcome measure with established content validity. This research confirms that the new 12-item Penn-FPS-R is easily understood and completed by individuals with $\mathrm{TN}$, and further, that it captures all important concepts related to $\mathrm{TN}$ pain interference on HRQoL and daily functioning. Interviews

Table 2 Penn-FPS-R items based on participant interviews

\begin{tabular}{|c|c|c|c|}
\hline Items & Amendment & $\begin{array}{l}\text { New Penn Facial Pain Scale- } \\
\text { Revised* }\end{array}$ & Item order \\
\hline \multicolumn{4}{|l|}{ Penn Facial Pain Scale* } \\
\hline Eating a meal & Remain unchanged. Identified in concept elicitation as eating & Eating a meal & 4 \\
\hline $\begin{array}{l}\text { Touching your face } \\
\text { (including grooming) }\end{array}$ & $\begin{array}{l}\text { Remain and edited. Identified in concept elicitation as } \\
\text { touching and self-care. Separated into touching face and } \\
\text { self-care items separately }\end{array}$ & $\begin{array}{l}\text { Touching your face (including } \\
\text { moving stray hairs, hugging, } \\
\text { kissing, itching) }\end{array}$ & 6 \\
\hline $\begin{array}{l}\text { Brushing or flossing your } \\
\text { teeth }\end{array}$ & $\begin{array}{l}\text { Remain unchanged. Identified in concept elicitation under } \\
\text { self-care }\end{array}$ & Brushing or flossing your teeth & 8 \\
\hline Smiling or laughing & $\begin{array}{l}\text { Remain unchanged. Not identified in concept elicitation, } \\
\text { supported in cognitive debrief }\end{array}$ & Smiling or laughing & 9 \\
\hline Talking & $\begin{array}{l}\text { Remain unchanged. Identified in concept elicitation as } \\
\text { talking }\end{array}$ & Talking & 10 \\
\hline $\begin{array}{l}\text { Opening your mouth } \\
\text { widely }\end{array}$ & $\begin{array}{l}\text { Remain unchanged. Not identified in concept elicitation, } \\
\text { supported in cognitive debrief }\end{array}$ & Opening your mouth widely & II \\
\hline $\begin{array}{l}\text { Eating hard foods like } \\
\text { apples }\end{array}$ & $\begin{array}{l}\text { Removed. Participants highlighted that biting or chewing } \\
\text { was more relevant }\end{array}$ & Removed & N/A \\
\hline New item & $\begin{array}{l}\text { New item. Based on participants' feedback to eating hard } \\
\text { foods question }\end{array}$ & Biting or chewing & 5 \\
\hline New item & $\begin{array}{l}\text { New item. Based on concept elicitation the item touching } \\
\text { face (including grooming) has been separated into self-care } \\
\text { and touching face to better reflect concept elicitation }\end{array}$ & $\begin{array}{l}\text { Self-care (including washing } \\
\text { face or hair, shaving, applying } \\
\text { makeup) }\end{array}$ & 7 \\
\hline New item & New item based on concept elicitation outside/weather & $\begin{array}{l}\text { Activities with temperature } \\
\text { change (moving outside, } \\
\text { between air-conditioned rooms) }\end{array}$ & 12 \\
\hline \multicolumn{4}{|l|}{ BPI-PII** } \\
\hline General activity & $\begin{array}{l}\text { Clearly identified in concept elicitation as daily activities } \\
\text { Amended to reflect this more specific wording }\end{array}$ & $\begin{array}{l}\text { Daily activities (for example, } \\
\text { work, exercise, and housework) }\end{array}$ & I \\
\hline Mood & $\begin{array}{l}\text { Clearly identified in concept elicitation } \\
\text { Amended to add clarity }\end{array}$ & Mood (the way you are feeling) & 2 \\
\hline $\begin{array}{l}\text { Relations with other } \\
\text { people }\end{array}$ & $\begin{array}{l}\text { Clearly identified in concept elicitation } \\
\text { Amended to add clarity using participants' own examples }\end{array}$ & $\begin{array}{l}\text { Relationships (for example, } \\
\text { friends, family, partners, etc.) }\end{array}$ & 3 \\
\hline Walking ability & $\begin{array}{l}\text { Removed, not clearly identified in concept elicitation nor } \\
\text { supported during cognitive debrief }\end{array}$ & Removed & N/A \\
\hline $\begin{array}{l}\text { Normal work } \\
\text { (includes both inside and } \\
\text { outside the home and } \\
\text { housework) }\end{array}$ & $\begin{array}{l}\text { Removed, not clearly identified in concept elicitation nor } \\
\text { supported during cognitive debrief }\end{array}$ & Removed & N/A \\
\hline Sleep & $\begin{array}{l}\text { Removed, not clearly identified in concept elicitation nor } \\
\text { supported during cognitive debrief }\end{array}$ & Removed & N/A \\
\hline Enjoyment of life & $\begin{array}{l}\text { Removed, not clearly identified in concept elicitation nor } \\
\text { supported during cognitive debrief }\end{array}$ & Removed & $\mathrm{N} / \mathrm{A}$ \\
\hline
\end{tabular}

Notes: *The content of the Penn Facial Pain Scale and the Penn Facial Pain Scale-Revised is included here with permission of John YK Lee. Copyright $@$ John YK Lee. **BPI copyright held by Charles S Cleeland, I99I. The items in column I under BPI-PII have been replicated to show how the PENN-FPS has been decoupled from the BPI with permission of Charles S Cleeland. The items are replicated from: Cleeland CS, Ryan KM. Pain assessment: global use of the Brief Pain Inventory. Ann Acad Med Singapore. 1994;23(2):129-138. ${ }^{19}$

Abbreviations: BPI-PII, Brief Pain Inventory Pain Interference Index; N/A, not applicable. 
were undertaken with 20 participants, which, given the nature of this rare condition, is a large sample and should provide confidence in the results. There were no differences identified between the UK and US cohorts, therefore, the measure content is appropriate for both countries.

The Penn-FPS-R retains all the concepts measured in the original version plus a new item assessing the impact of weather/temperature. The Penn-FPS-R also includes 3 of the 7 concepts assessed by the BPI-PII: "daily activities (for example, work, exercise, and housework)," "mood (the way you are feeling)," and "relationships (for example, friends, family, partners, etc.)." Minor edits were required to improve the sensitivity of some specific items. For example, the original Penn-FPS had one item on "touching your face (including grooming)." Interviews suggested that this item would be improved by breaking it into two separate questions involving "touching your face (including moving stray hairs, hugging, kissing, itching)" and "self-care (including washing face or hair, shaving, applying makeup)." The original Penn-FPS also included an item on the impact of "eating hard food." Participants indicated that the item would more accurately capture their experience if it assessed the impact of foods that were difficult to chew or bite. More specificity was also needed to accurately assess the impact of pain on "social relationships." Participants emphasized that TN adversely affected relationships that involved kissing and/or being with others who were close enough to bump against their faces, which was addressed by addition of the item "touching your face (including moving stray hairs, hugging, kissing, itching)" and clarification of the item "relationships (for example, friends, family, partners, etc.)." By refining some specific items and decoupling the Penn-FPS from the BPI-PII, the resulting Penn-FPS-R represents a shorter and more relevant outcomes assessment option in TN.

The adequacy of any patient reported outcome instrument (whether existing, modified, or newly developed) as a measure to support medical product labeling claims depends on whether its characteristics, conceptual framework, content validity, and other measurement properties are satisfactory. ${ }^{14}$ Content validity is the extent to which the instrument measures the concept of interest. With the existing Penn-FPS, it cannot be assumed that it has content validity since patients were not involved in instrument development. This new qualitative work provides documentation of content validity for the Penn-FPS-R since patient interviews were conducted using open-ended methods to elicit patient input. The findings of this study provide evidence that the Penn-FPS-R measures the concepts of most importance to patients. Furthermore, this research confirms that the items and domains are appropriate and comprehensive relative to its intended measurement concept, population, and use.

The results of this study clearly show the high disease burden of this condition, which mirrors previous research. ${ }^{5-7}$ It also highlights that patients report a range of avoidance behaviors for fear of triggering their pain. ${ }^{8}$ Despite patients receiving current or past treatments, the average pain was still quite high (mean pain of $6.85[\mathrm{SD}=2.34]$ on a $0-10$ point NRS). This indicates a need for more effective disease management as well as the use of a TN-specific measure to help assess outcomes. The study findings demonstrate the utility of the new Penn-FPS-R for use in future research and clinical practice to assess HRQoL. Future studies are needed to assess the psychometric properties and cross-cultural validity of this newly developed measure.

\section{Conclusion}

Results from this qualitative study were applied to develop the Penn-FPS-R, a brief 12-item outcome measure, with established content validity that can be used to assess the impact of $\mathrm{TN}$ pain and treatment outcome in both clinical practice and research.

\section{Acknowledgment}

This research was funded by Biogen.

\section{Disclosure}

Joanna M Zakrzewska undertook this work at University College London/University College London Hospitals Trust, the recipients of a proportion of funding from the UK Department of Health's National Institute for Health Research Biomedical Research Centre funding scheme. Deborah L Hoffman was an employee of Biogen Inc. at the time of the study, but is no longer an employee of Biogen Inc. The other authors report no conflicts of interest in this work.

\section{References}

1. Dieleman JP, Kerklaan J, Huygen FJ, Bouma PA, Sturkenboom MC. Incidence rates and treatment of neuropathic pain conditions in the general population. Pain. 2008;137(3):681-688.

2. Hall GC, Carroll D, Parry D, McQuay HJ. Epidemiology and treatment of neuropathic pain: the UK primary care perspective. Pain. 2006;122(1):156-162.

3. Katusic S, Beard C, Bergstralh E, Kurland L. Incidence and clinical features of trigeminal neuralgia, Rochester, Minnesota, 1945-1984. Ann Neurol. 1990;27(1):89-95.

4. [No authors listed]. Classification of chronic pain. Descriptions of chronic pain syndromes and definitions of pain terms. Prepared by the International Association for the Study of Pain, Subcommittee on Taxonomy. Pain Suppl. 1986;3:S1-S226. 
5. Adams H, Pendleton C, Latimer K, Cohen-Gadol A, Carson B, Quinones-Hinojosa A. Harvey Cushing's case series of trigeminal neuralgia at the Johns Hopkins Hospital: a surgeon's quest to advance the treatment of the 'suicide disease'. Acta Neurochir (Wien). 2011;153(5):1043-1050.

6. Tolle T, Dukes E, Sadosky A. Patient burden of trigeminal neuralgia: results from a cross-sectional survey of health state impairment and treatment patterns in six European countries. Pain Pract. 2006;6(3): $153-160$.

7. Zakrzewska JM, Wu J, Mon-Williams M, Phillips N, Pavitt SH. Evaluating the impact of trigeminal neuralgia. Pain. 2017;158(6): 1166-1174.

8. Allsop MJ, Twiddy M, Grant H, et al. Diagnosis, medication, and surgical management for patients with trigeminal neuralgia: a qualitative study. Acta Neurochir (Wein). 2015;157(11):1925-1933.

9. Chen HI, Lee JY. The measurement of pain in patients with trigeminal neuralgia. Clin Neurosurg. 2010;57:129-133.

10. Lee J, Chen H, Urban C, et al. Development of and psychometric testing for the Brief Pain Inventory-Facial in patients with facial pain syndromes. J Neurosurg. 2010;113(3):516-523.

11. Sandhu SK, Halpern CH, Vakhshori V, Mirsaeedi-Farahani K, Farrar JT, Lee JY. Brief Pain Inventory-Facial minimum clinically important difference. J Neurosurg. 2015;122(1):180-190.
12. Lee J. Measurement of trigeminal neuralgia pain Penn Facial Pain Scale. Neurosurg Clin N Am. 2016;27:327-336.

13. Zakrzewska JM. Insights: Facts and Stories Behind Trigeminal Neuralgia. Gainesville: Trigeminal Neuralgia Association; 2006.

14. US Food and Drug Administration. Guidance for Industry. PatientReported Outcome Measures: Use in Medical Product Development to Support Labeling Claims. US Department of Health and Human Sciences. 2009. Available from: http://www.fda.gov/downloads/Drugs/.../ Guidances/UCM193282.pdf. Accessed September 5, 2016.

15. Willig C. Introducing Qualitative Research in Psychology. Maidenhead: McGraw-Hill Education; 2013.

16. Green J, Thorogood N. Qualitative Methods for Health Research. London: Sage; 2013.

17. World Medical Association. World Medical Association Declaration of Helsinki. Ethical principles for medical research involving human subjects. Bull World Health Organ. 2001;79(4):373.

18. Braun V, Clarke V. Using thematic analysis in psychology. Qual Res Psychol. 2006;3(2):77-101.

19. Cleeland CS, Ryan KM. Pain assessment: global use of the Brief Pain Inventory. Ann Acad Med Singapore. 1994;23(2):129-138.

\section{Journal of Pain Research}

\section{Publish your work in this journal}

The Journal of Pain Research is an international, peer reviewed, open access, online journal that welcomes laboratory and clinical findings in the fields of pain research and the prevention and management of pain. Original research, reviews, symposium reports, hypothesis formation and commentaries are all considered for publication.

\section{Dovepress}

The manuscript management system is completely online and includes a very quick and fair peer-review system, which is all easy to use. Visit http://www.dovepress.com/testimonials.php to read real quotes from published authors. 